\title{
NOTAS SOBRE O CONCEITO DE VERDADE EM NIETZSCHE E RORTY: ATRAVESSAMENTOS
}

\author{
NOTES ON THE CONCEPT OF TRUTH IN NIETZSCHE AND RORTY: \\ CROSSES
}

\author{
Glaucer Ferreira Silva ${ }^{1}$ \\ ferreiraglaucer@gmail.com
}

\begin{abstract}
RESUMO: O estudo em questão tem por intuito buscar, em um primeiro momento, explicitar o modo pelo qual a crítica do filósofo alemão Friedrich Nietzsche (1844-1900) se insere na história da filosofia, com ênfase em sua crítica sobre a ideia de Verdade. Como aporte teórico, nos deteremos sobre os textos: Sobre verdade e mentira no sentido extramoral (1873); Além do bem e do mal (1886) e A genealogia da moral (1887). Já em um segundo momento, apontaremos para o filósofo neopragmatista norte-americano Richard Rorty (1931-2007) e sua postura quanto à mesma questão, apresentando suas particularidades e seus conceitos mais fundamentais acerca dessa problemática. Utilizaremos para tal fim os textos rortyanos: Filosofia Como Politica Cultural (2009) e Ensaios sobre Heidegger e outros (1999), entre outros. O fio que buscaremos demostrar entre esses dois filósofos passa pela postura crítica que estes apresentam quanto ao modo como se posicionam ante a ideia de Verdade. A iconoclastia nietzschiana e a busca por uma postura edificante e redescritivista rortyana tem como ponto fulcral, a nosso ver, a negação de uma postura estática relativa à forma de se fazer filosofia aos moldes essencialistas e representacionistas. Não estamos, contudo, dizendo que Rorty seja um continuador das ideias propostas por Nietzsche, mas que podemos encontrar pontos de covergências quanto a suas propostas. No terceiro tópico argumentamos que a filosofia nietzschiana apresenta momentos de aproximação quanto à perspectiva pragmatista, bem como distanciamentos.
\end{abstract}

PALAVRAS-CHAVE: Nietzsche. Rorty. Verdade. Crítica. Filosofia.

ABSTRACT: The study in question aims to seek, at first, to explain the way in which the critic of the German philosopher Friedrich Nietzsche (1844-1900) is inserted in the history of philosophy, with emphasis on his criticism about the idea of Truth. As a theoretical contribution, we will focus on the texts: On truth and lies in the extramoral sense (1873); Beyond good and evil (1886) and The genealogy of morals (1887). In a second step, we will point to the American neopragmatist philosopher Richard Rorty (1931-2007) and his stance on the same issue, presenting his particularities and his most fundamental concepts about this problem. For this purpose, we will use the Rortyan texts: Philosophy as Cultural Policy (2009) and Essays on Heidegger et al. (1999), among others. The thread that we will try to demonstrate between these two philosophers goes through the critical posture that they present regarding the way they position themselves before the idea of Truth. The Nietzschean iconoclasm and the search for an edifying and rediscounting posture from Rortyana has as its central point, in our view, the denial of a static posture regarding the way of doing philosophy in the essentialist and representational molds. We are not, however, saying that Rorty is a continuator of the ideas proposed by Nietzsche, but that we can find points

\footnotetext{
${ }^{1}$ Graduado em Letras-Português e em Filosofia pela Universidade Estadual do Piauí-UESPI. Atualmente é mestrando do Programa de Pós-Graduação em Filosofia pela Universidade Federal do Piauí-UFPI (PPGFIL). Tenho especial interesse por temas da filosofia nietzcheana com ênfase na elaboração estética apresentada pelo referido autor.
} 
of coverage regarding his proposals. In the third topic, we argue that Nietzschean philosophy presents moments of approximation regarding the pragmatist perspective, as well as distances.

KEYWORDS: Nietzsche. Rorty. Truth. Criticism. Philosophy.

\section{1- Introdução}

O filósofo alemão Friedrich Nietzsche (1844-1900) é certamente um dos principais críticos quanto à ideia de "verdade" na história da filosofia. Jamais abandonando tal problema ao longo de sua produção filosófica. Em obras como Sobre verdade e mentira no sentido extramoral (1873), Além do bem e do mal (1886) e $A$ genealogia da moral (1887), podemos vislumbrar o projeto crítico apontado pelo autor quanto a este conceito e suas implicações. Um de seus principais alvos quanto a este tema é certamente a tríade Platão/Descartes/Kant, exatamente por seu cognitivismo; juntamente com o ideário proposto pelo cristianismo e suas consequências morais e culturais.

É tendo em vista a crítica à ideia de $\operatorname{Verdade}^{2}$ que propomos a contribuição de outro filósofo nessa discussão, exatamente por acreditarmos que este também se mostra avesso a ideia de Verdade, ou seja, uma crítica às bases de sustentação da filosofia. Tal pensador é o neopragmatista Richard Rorty.

Acreditamos que ambos apresentam aproximações quanto a crítica a ideia de Verdade, mas que possuem posturas antagônicas, principalmente relacionadas às concepções apresentadas no campo da política. Contudo, o que nos interessa neste estudo é a crítica que apresentam quanto à formulação da ideia de Verdade e suas principais consequências quanto aos rumos desse debate tão caro à história da filosfia tradicional.

Deste modo, no primeiro tópico deste estudo buscaremos entender a crítica à ideia de verdade inserida na filosofia nietzschiana, utilizando as supracitadas obras como fundamentação nesse primeiro momento do texto. Posteriormente, no segundo tópico privilegiaremos a perspectiva rortyana do problema da Verdade. Richard Rorty (1931-2007) foi um filósofo norteamericano de profunda influência na filosofia contemporânea. Apontado como um dos principais representantes do neopragmatismo e um dos principais nomes da filosofia nos últimos tempos. É tendo em vista sua crítica à ideia de Verdade, bem como de seus pressupostos filosóficos, que propomos sua contribuição nesta pesquisa.

Rorty também se mostra avesso à ideia de verdade, de fundamentos últimos e de metafísicas primeiras, praticando a assim chamada metafilosofia, ou seja, uma crítica às bases de sustentação da filosofia utilizando a própria linguagem filosófica, contudo a filosfia rortyana não é uma filosofia

\footnotetext{
${ }^{2}$ Doravante utilizamos a ideia de verdade com V maiúsculo, advinda da tradição filosfófica iniciada com Platão, para diferenciar de perspectivas outras.
}

Cadernos Cajuína, V. 6, N. 1, 2021, p. 69-83. 
negativa, mas uma postura que vê na ação cultural e política a chave para a construção de uma sociedade menos cruel e mais solidária. No terceiro tópico deste estudo buscaremos demostrar, via crítica, o modo pelo qual Nietzsche é visto como um possível pragmatista por Rorty. Daremos destaque, neste tópico, à obra rortyana Filosofia como política Cultural (2009), bem como outros textos do autor como aporte teórico.

\section{2-Nietzsche, Verdade, conhecimento e crítica à modernidade}

Nietzsche sugere que a ideia de Verdade na ciência acaba por esterilizar a vida, e se mostra uma busca alucinada por fundamentos últimos e princípios primeiros. O filósofo aponta para a arte como redentora da vida, exatamente pelo seu caráter criativo ligado à imaginação. $\mathrm{O}$ niilismo ${ }^{3}$, ou o vazio moderno é deste modo, perscrutado pelo filósofo trágico, Nietzsche. Entendemos que há em Nietzsche a centelha dos problemas mais relevantes na contemporaneidade, como a linguagem e de como esta resvalará em questões epistêmicas e políticas, bem como morais e éticas.

Tal crítica aos valores modernos assenta-se na suspeita de que a ideia de Verdade pauta-se em conceitos ligados ao essencialismo ${ }^{4} /$ teleológico fundacionista ${ }^{5}$, que, como sabemos, é um dos pilares principais de sustentação do edifício filosófico ocidental, bem como suas ramificações. Sobre o platonismo, segundo a visão do autor, é evidente que se trata de um momento de cisão na história da filosofia entre mundo sensível e mundo inteligível. O que significa compreender que o fundamento último para um juízo moral e epistemológico, estaria fora, em um mundo suprassensível, inalcançável. Restando-nos apenas o aparente e ilusório mundo dos sentidos, que por sua vez também não nos traria respostas definitivas.

Poderíamos pensar, seguindo o fio nietzschiano, que, talvez, não precisássemos de uma resposta, mas de uma reformulação das questões elencadas como centrais, ou imaginar uma filosofia outra, sem fundamentos e antiessencialista onde a ideia de verdade estaria ligada a um fim prático. É tendo em vista que é o homem quem possui tal poder criativo, e na filosofia essa

\footnotetext{
${ }^{3}$ Vale ressaltarmos que o niilismo proposto por Nietzsche difere-se daquele que o precede, enquanto que na primeira acepção do termo niilismo significa vazio, para o autor o sentido é exatamente o oposto. Niilismo seria o preenchimento da vida por valores inferios, inferiores significando valores que diminuiriam a vida, tornando-a um fardo. Nietzsche popõe a trasnvaloração do termo, ou seja, um novo valor, não um potencialização do precedente. ${ }^{4}$ Essa metafísica clássica, indicada pelo platonismo, é entendida como uma crença na distinção de dois mundos, pela oposição entre essência e aparência, verdadeiro e falso, inteligível e sensível, ou seja, através de dualismos. Essa metafísica faz da vida qualquer coisa que deve ser avaliada, julgada, limitada e, do pensamento, uma medida, um limite, que se exerce em nome de valores superiores (o divino, o verdadeiro, o belo, o bem). Por isso Nietzsche usa a palavra valorar em vez de valorizar. Para o filósofo existe a necessidade de valoração da ideia de verdade. É importante destacar que o "essencialismo" é fruto de uma interpretação específica do platonismo, que se tornou a mais corrente. Hoje ela já é reavaliada de outro modo pelos comentadores mais atuais.

${ }^{5}$ Grosso modo, podemos compreender o fundacionalismo como um tipo de dispositivo que visa desvencilhar-se do chamado regresso epistêmico, ou seja, pretende fundar bases seguras quanto à possibilidade do conhecimento, oferecendo, desse modo crenças básicas ou fundamentos "seguros".
} 
expressão criativa se dá através dos conceitos, que o autor nos propõe a seguinte passagem. "Enquanto gênio da arquitetura, o homem supera em muito a abelha: esta constrói com a cera que recolhe da natureza, o homem o faz com a matéria bem mais frágil dos conceitos que é obrigado a fabricar com seus próprios meios”. (NIETZSCHE, 2001, p.14). É justamente nesse ponto que o homem, segundo o autor, se mostra superior à natureza, pois é necessário fabricar as ferramentas de que necessita, enquanto que a natureza não. O que estamos tentando apontar com essa passagem é que a ideia de Verdade também foi fabricada pelo homem para um determinado fim; e na proposta nietzschiana encontra-se vinculada à ideia de dominação.

Com relação ao valor da ideia de Verdade, Nietzsche nos alerta sobre as veredas espinhosas que tal busca iria nos conduzir:

O amor pela verdade que nos conduzirá a muitas perigosas aventuras, essa famosíssima veracidade de que todos os filósofos sempre falaram respeitosamente — quantos problemas já nos colocou! E problemas singulares, malignos, ambíguos! Apesar da velhice da estória, parece que acaba de acontecer. Se acabássemos, por esgotamento, sendo desconfiados e impacientes, que haveria de estranho? É estranhável que essa esfinge nos tenha levado a nos formular toda uma série de perguntas? Quem afinal vem aqui interrogar-nos? Que parte de nós tende "para a verdade?" Detivemo-nos ante o problema da origem dessa vontade, para ficar em suspenso diante de outro problema ainda mais importante? Interrogamo-nos sobre o valor dessa vontade. (NIETZSCHE, 2001, p.11)

Nietzsche é considerado como o filósofo da suspeita. Exatamente pelo posicionamento que apresenta quanto pretende transvalorar ${ }^{6}$ os valores seculares que nos foram apresentados como Verdadeiros pela tradição, propondo uma busca pela verdade não metafísica e não preconceituosa. É tendo em vista este horizonte crítico que Nietzsche afirma que "A crença fundamental dos metafísicos é a crença na antítese dos valores" (NIETZSCHE, 2014, p.13). Deste modo o autor aponta para o erro dos dualistas em dicotomizar a vida e, principalmente, buscar valorá-la usando uma gramática ligada a uma postura ressentida.

Para o filósofo alemão as verdades são:

Uma multidão móvel de metáforas metonímias e antropomorfismos; em resumo, uma
soma de relações humanas que foram realçadas, transpostas e ornamentadas pela poesia
e pela retórica e que, depois de um longo uso, pareceram estáveis, canônicas e
obrigatórias aos olhos de um povo: as verdades são ilusões das quais se esqueceu que são,
metáforas gastas que perderam a sua força sensível, moeda que perdeu sua efígie e que
não é considerada mais como tal, apenas como metal. (NIETZSCHE, 2001, p.12)

\footnotetext{
${ }^{6} \mathrm{O}$ projeto de transvoloração de todos os valores proposto por Nietzsche é um dispositivo que tem como fim buscar livrar a vida de valores que advindos de uma postura de ressentimento e de desprezo pela própria vida, ou seja, colocar os valores seculares sobre suspeita para em seguida propor uma nova postura ligada à criação de si. O projeto de transvaloração busca deformar ou inverter os "valores eternos".
} 
Por conseguinte, o filósofo aponta para a Verdade como o produto de uma transposição sonora para uma palavra, que por sua vez torna-se conceito e por exercício de fixação se incrusta na história do pensamento através da força, ganhando em seguida o valor de Verdade. A história da Verdade seria a história de uma mentira perpetuada e tornada verdadeira além de uma sucessão de metáforas, ou seja, transposições instintivas lidadas tanto ao desejo de dominação como de convencimento através da força do discurso.

Ademais, o mundo ilusório metafísico platônico, se apoia na ideia de Verdade advinda da vontade de engano e acaba por degenerar a vida, retirando-lhe tudo aquilo que a tornaria digna de ser vivida. Nietzsche considera a perspectiva platônica dualista um erro, e propõe que "Admitir o erro como condição da vida é rebelar-se contra os atuais conceitos de valor, e uma filosofia que a tal se atreve colocar-se por isso além do bem e do mal" (NIETZSCHE, 2014, p.15). Ou seja, Nietzsche aposta em uma filosofia assentada na dúvida, no talvez, que coloque em suspensão os valores que até então foram postos como valores supremos, tais como: verdade, realidade e Deus. Nietzsche parece apontar para a necessidade do surgimento de filósofos que ousem se voltar contra a história da filosofia, lançando sobre esta um olhar de desconfiança e suspeita, em suma, de um talvez.

Talvez! Mas, quem cuida de uns 'talvezes' tão perigosos? Para que isso suceda é preciso esperar o advento de uma nova espécie de filósofos, que tenham inclinações e gostos diametralmente opostos aos atuais. Filósofos do perigoso 'talvez' em todos os sentidos. E falando seriamente parece-me que os vejo surgir. (NIETZSCHE, 2014, p.13)

E evidente que a escola da suspeita pensada por Nietzsche também tem em mira outros grandes sistemas filosóficos, como o oferecido por Descartes e Kant, tecendo críticas às suas bases de sustentação e tencionando miná-las. Fica evidente, portanto, que não apenas o platonismo, mas também o cartesianismo, com a "invenção" do cogito, e o kantismo com seus juízos categóricos, foram pensados por Nietzsche como impraticáveis. Nietzsche aponta a produção desses pensadores como fazendo parte de uma tradição largamente fantasiosa.

A propósito do Kantismo, Nietzsche nos informa que, "Kant estava muito orgulhoso de sua tábua de categorias e costumava dizer com ela na mão: 'Esta é a coisa mais difícil que já foi inventada na metafísica."'(NIETZSCHE, 2014, p.20). Kant apostava em algo que parecia ter encontrado através da faculdade de uma faculdade, “[...] naqueles tempos em que 'achar' e 'inventar' tinham o mesmo significado". (NIETZSCHE, 2014, p.21). Para Nietzsche, a ideia de Verdade também é uma invenção, que assim como os outros conceitos foi inventada e aprimorada para servir a um determinado fim. Mas o homem, segundo pensa o autor, começou a despertar e refletir 
sobre o valor dos valores, inclusive sobre a verdade sobre a Verdade. "[...] veio um tempo em que começou a gente a esfregar os olhos, e ainda hoje muita os estão esfregando. Viu-se que era um sonho: quem antes de todos, primeiro o sonhou foi o velho Kant.” (NIETZSCHE, 2014, p.21). A vontade de Verdade, enfim, tornou-se vontade de engano.

Nietzsche é um filósofo vitalista que vê na vida uma potência sempre criativa e fecunda, atacando ferrenhamente todos àqueles que buscam diminuí-la. Daí seu desprezo pelos sistemas filosóficos fechados em si mesmos, que se utilizam da linguagem metafísica para degenerar a vida, cingindo-a com seus dualismos estéreis. Nietzsche pratica o que ele denomina de fisiologia do pensamento. O Homem deveria pensar com todo seu corpo, de forma intensa e longe da metafísica. A verdade seria aquela produzida pelo próprio corpo. Neste ponto podemos apontar para uma centelha pragmatista ${ }^{7}$ em Nietzsche, quando este oferece uma espécie de giro paradigmático no tocante aos princípios epistemológicos oferecidos pela modernidade. Pondo sob dúvida seus fundamentos.

Dirá, nesse sentido, o filósofo, em Para Além do bem e do Mal:

[...] já é, por fim, hora de substituir a proposição kantiana 'como são possíveis os juízos sintéticos a priori?’ com esta outra: e por que é necessário acreditar em tais juízos?' e de compreender que semelhantes juízos devem ser tidos por verdadeiros para a conservação dos seres de nossa espécie; mas isso não impede que possam ser também falsos! E para falar com mais franqueza grosseira e fundamental: os juízos sintéticos a priori não devem ser possíveis; não temos nenhum direito sobre os mesmos, em nossa boca são apenas juízos falsos (NIETZSCHE, 2014, p.21).

Saímos, portanto de uma visão unilateral e desértica, para múltiplas leituras de um mesmo fenômeno, ou seja, de uma perceptiva para um perspectivismo ${ }^{8}$. Com isso pretendemos dizer, em consonância com a proposta nietzschiana, que a história da Verdade é uma perspectiva da verdade. E para a perspectiva metafísica, a Verdade residiria em outro mundo, mas influenciaria moralmente o "mundo de cá".

A vontade de verdade é posta por Nietzsche como elemento vital, coesivo e agregador. Como um dínamo disparador para a vontade de engano. Gostaríamos, seguindo essas linhas, de salientar que acreditamos que há em Nietzsche passagens e posturas que nos fazem remeter ao

\footnotetext{
${ }^{7} \mathrm{O}$ pragmatismo é uma corrente filosófica baseada na finalidade prática da filosofia, utilizando noções "antirepresentacionistas" da realidade. Tem por representantes três filósofos principais: Charles S. Peirce, Willian James e John Dewey. Posteriormente oferecemos um trato pormenorizado quanto a essa vertente filosófica.

${ }^{8} \mathrm{O}$ perspectivismo é uma espécie de proliferação de distintas interpretações que tem o dilaceramento dos horizontes interpretativos como marca. Segundo Nietzsche quanto ao perspectivismo. "[...] quanto mais afetos permitirmos falar sobre uma coisa, quanto mais olhos, diferentes olhos, soubermos utilizar para essa coisa, tanto mais completo será o nosso 'conceito' dela, nossa "objetividade". (NIETZSCHE, 2009, p. 109).
} 
pragmatismo. Talvez pela ênfase na experiência guiada pela imaginação e pelo poder criativo ligado a fins úteis para a vida do homem em sociedade. A escrita nietzschiana é extremamente experimental. Postura esta que alarga os horizontes ligados à criação. Há outra característica que nos faz lembrar a quebra com o modo tradicional de se fazer filosofia em Nietzsche, a saber, a questão: por que e para que a verdade?

Pensamos que o problema da verdade em Nietzsche surge como um dispositivo voltado para a cessação do estado beligerante contemplado pela perspectiva hobbesiana, o chamado Estado de Natureza. É nessa direção que o autor no coloca que:

No estado de natureza, na medida em que o indivíduo quer conservar-se diante dos outros indivíduos, ele não utiliza sua inteligência o mais das vezes senão com fins de dissimulação. Mas, na medida em que o homem, ao mesmo tempo por necessidade e por tédio, quer viver em sociedade e no rebanho, necessário lhe é concluir a paz e, de acordo com este tratado, fazer de modo tal que pelo menos o aspecto mais brutal do bellum omnium contra omnes desapareça do seu mundo. (NIETZSCHE, 2001, p.9)

A verdade estaria nas mãos do mais forte, e tal imposição se daria pela força do argumento em detrimento do argumento da força. Contudo o mais forte nem sempre é o mais capaz.

Faz-se indispensável notar que a filosofia nietzschiana é uma filosofia que parte da noção de ruptura, de torção, e, principalmente de uma postura crítica. A principal contribuição de Nietzsche é pensar uma pesrpectica não-dualista.

\section{1- Rorty, redescrição, ${ }^{9}$ Verdade e neopragmatismo}

É tendo em vista a crítica à ideia de Verdade, que indicamos as contribuições de Richard Rorty (1931-2007). Filósofo norte-americano de profunda influência na filosofia contemporânea. Apontado como um dos principais representantes do neopragmatismo, Rorty também se mostra avesso à ideia de Verdade canonizada pela tradição filosófica, e similarmente a Nietzsche, crivará os fundamentos filosóficos.

A filosofia rortyana tem como foco a linguagem, enquanto que "os pragmatistas mais antigos como Dewey, em contraste, falavam de 'experiência' em vez de 'linguagem” (RORTY, 1991, p. 269). O pragmatismo é uma corrente filosófica baseada na finalidade prática da filosofia traduzida em alternativas úteis, utilizando-se de noções antirrepresentacionistas ${ }^{10} \mathrm{e}$

\footnotetext{
${ }^{9}$ Sobre este método Rorty nos informa que "o Método consiste em descrever uma porção de coisas de maneira novas, até criar um padrão de conduta linguística que tende a geração em ascensão a adotá-la, com isso fazendo-a buscar novas formas apropriadas de comportamento não linguístico - por exemplo, a adoção de um novo equipamento científico ou de novas instituições sociais”. (RORTY, 2007, p.34).

10 O representacionismo se resume em representar o mundo, relacionando-o a algo universal, essencial.
} 
antifundacionistas, lançando duras críticas às ideias derivadas da História da Filosofia e seus pressupostos. O pragmatismo tem como representantes a tríade: Charles S. Pierce, Willian James e já citado John Dewey. Sendo este último o mais prestigiado por Rorty.

O pragmatismo é traduzido por Rorty como uma esperança social. Tal esperança estaria amparada em uma nova forma de se filosofar, presente em filósofos que Rorty denomina de edificantes, em contraposição os filósofos sistemáticos, como Kant e Platão. Sobre tal distinção Rorty, no texto $A$ Filosofia e o espelho da natureza, mais especificamente no capítulo $A$ filosofia sem espelhos, no informa que "Os filósofos da corrente principal são os filósofos que chamarei ‘sistemáticos', e os periféricos são aqueles que chamarei ‘edificantes”' (Rorty, 1994, p.361). Os filósofos pragmatistas se enquadram nessa segunda denominação, exatamente pelo seu posicionamento cético em relação aos sistemáticos por acreditarem que a partir de seus sistemas possam ter acesso a verdades últimas e princípios primeiros pelo fio correspondentista.

A crítica antiessencialista e antimetafísica se mostra clara no pensamento rortyano. Quanto à crítica ao essencialimo e o posicionamento de Nietzsche e Heidegger, ambos ditos antimetafísicos, Rorty nos informa que:

Isso vem à tona de modo muito claro em nossa propensão recente para falarmos sobre o 'ocidente' não como uma aventura contínua e cheia de suspenses, da qual nós estamos participando, mas, ao contrário, como uma estrutura da qual podemos nos separar para inspecioná-la à distância. Essa propensão é parcialmente a causa e parcialmente o efeito da profunda influencia de Nietzsche e Heidegger na vida intelectual do ocidente contemporâneo. (RORTY, 1999, p.96)

Rorty propõe com seu pensamento uma profunda crítica aos conceitos apresentados pela postura representacionista tradicional e seu consequente modo de se fazer filosofia, oferecendo a redescrição como um modo alternativo de se propor soluções emergenciais para os problemas políticos e éticos. A filosofia para Rorty rompe com os fundamentos advindos da filosofia clássica e moderna, praticando uma crítica aguda aos pseudoproblemas apresentados pela metafísica, seja ela antiga ou contemporânea.

Ainda sobre a filiação de Rorty ao pragmatismo temos a seguinte passagem do texto Relativismo: Encontrar e Fabricar, onde o filósofo aponta as críticas que o pragmatismo sofre por parte de seus opositores.

Geralmente nos definimos em termos negativos: somos antiplatônicos, ou antimetafísicos, ou, ainda, antifundacionistas. Do mesmo modo, nossos oponentes raramente se chamam a si mesmos platônicos, metafísicos ou fundacionistas, mas costumam intitular-se defensores do senso comum, ou da razão. (RORTY, 1994, p.116). 
Nesse mesmo texto, Rorty aponta Nietzsche como um filósofo relativista por apostar na ideia de que "a verdade é a vontade de dominar a multiplicidade de sensações", mas também àqueles que estão em concordância com o pensamento de Willian James e Kuhn. Para o primeiro "verdade é simplesmente aquilo que favorece o ato de acreditar", enquanto que para os demais, "é um erro pensar que a ciência se encaminha para uma representação acurada do mundo como ele é por si mesmo". (RORTY, 1999, p.115). Rorty define como relativistas aqueles “que não acreditam na distinção grega entre as coisas como elas são por si mesmas e suas relações com as outras coisas, e, em particular, com as necessidades e interesses dos humanos". (RORTY, 1999, p.115). Essa passagem nos mostra a possibilidade de concordância entre o projeto rortyano e seu holismo, com a proposta nietzschiana do além do homem. Isso se aceitarmos esse além, não como metafísico, mas como possibilidade de superação do homem socrático/platônico, ou seja, como uma ruptura com o modelo grego e possibilidade de pensarmos em saídas outras daquelas imaginadas pelos helenos. Há neste tocante, sobretudo, clara crítica ao ideal racionalista grego.

Tanto Nietzsche como Rorty são acusados de serem irracionalistas por não corroborarem com tal modelo de pensamento. Contudo Rorty vai adiante e considera infrutífero se debruçar sobre tais distinções, sejam elas entre encontrar e fabricar, ou seus correlatos tais como subjetividade/objetividade, ideias intrínsecas/extrínsecas. "Acho importante que nós, que somos acusados de relativismo, deixemos de lado essas distinções entre encontrar e fabricar, entre descoberta e a invenção, entre objetivo e subjetivo”. (RORTY, 1994, p.118).

Rorty deixa claro que não é relativista pelo simples fato de não se deixar inserir no vocabulário proposto por seus adversários. Desta maneira, Rorty sai em defesa do pragmatismo e declara que:

\footnotetext{
Não podemos deixar que os nossos oponentes nos imponham o vocabulário que usam, temos que repudiar esse vocabulário - o que equivale a dizer, mais uma vez, que devemos evitar o platonismo e a metafísica, no sentido lato da metafísica, o mesmo sentido no qual Heidegger afirmou que metafísica é platonismo. (RORTY, 1999, p. 118).
}

O que Rorty busca enfatizar nessa passagem é sua aposta antidualista à distinção, também dualista, entre encontrar e fabricar, desvencilhando-se do epíteto de relativista.

O neopragmatismo rortyano não busca validar conceitos universais, tão pouco teorizar acerca da Verdade em filosofia, mas demostrar a possibilidade, via criação, de se desprender das estruturas preestabelecidas pela história da filosofia. Rorty é um filósofo que lança mão da proposta contingencial no trato com as questões advindas da filosofia.

Deste modo, nota-se, que a linguagem ocupa lugar fundamental na produção rortyana, por propiciar a experiência criativa ligada à capacidade imaginativa ao invés de uma única representação. 
A imutabilidade da ideia de verdade, pensada ao longo de séculos por vários pensadores, dilui-se no poder criativo/imaginativo. Há deste modo a substituição das ideias de racionalidade e de essências inalteráveis como fundadoras do conceito de verdade, pelo caráter redescritivo assim como a possibilidade de se pensar de forma outra as soluções para os problemas do homem contemporâneo. O anti-representacionismo configura-se, portanto, como marca fundamental da proposta pragmática quanto à produção de conhecimento.

Segundo Rorty:

Uma abordagem anti-representacionista sugere que abandonemos a distinção grega entre aparência e realidade e a substituamos pela distinção entre meios de descrição do mundo que achamos úteis para certos propósitos e os meios que achamos úteis para outros propósitos. (RORTY, 1991, p. 265).

O pragmatismo seria uma teoria sobre a verdade, onde por verdade entende-se algo funcional e útil, que nos traria resultados práticos a depender da finalidade pretendida. As crenças dessa perspectiva devem ser de algo que funciona que traga certa vantagem, ou seja, segundo o autor: "nós, pragmatistas, não concordamos com a ideia de que devemos buscar a verdade pela verdade - não podemos considerar a verdade como a meta de uma investigação”. (RORTY, 1994, p.125). Portanto, não há uma Verdade em Rorty, mas verdades funcionais e úteis para determinados fins.

\section{2 - Nietzsche como um pragmatista romântico}

Em Romantismo como politeísmo romântico, Rorty (2009) faz menção a um texto surgido em Paris no ano de 1951, denominado Um romantismo utilitário: estudo sobre o movimento pragmatista. Texto em que o autor René Berthelot afirma existir um movimento intelectual que aproxima nomes importantes da filosofia, tais como: William James, John Dewey, Nietzsche, Bergson e Poincaré. Segundo Rorty, "Ele", Berthelot, "reconstituiu retroativamente as raízes românticas do pragmatismo por trás de Emerson até Schelling e Hoelderlin e as raízes utilitaristas até a influência de Darwin e Spencer” (RORTY, 2009 p.57).

É Berthelot, conforme Rorty, quem aponta o pragmatismo como um utilitarismo romântico, assinalando que esta característica seria, "seu vício mais particular e sua fraqueza oculta", ao passo que indica, que este "foi provavelmente o primeiro a chamar Nietzsche de 'um pragmatista alemão', e o primeiro a enfatizar a semelhança entre o perspectivismo deste e a teoria pragmatista da verdade (RORTY, 2009, p.58)". Temos explicitado nessa passagem a ideia de que o perspectivismo nietzschiano se ligaria, de algum modo, às características encontradas no 
pragmatismo rortyano, como o deslocamento e a contigência ${ }^{11}$. Talvez por se tratarem de filósofos multifacetados.

Seguindo esse fio, apresentado no supracitado texto, identificamos a filosofia nietzschiana, que coloca os homens como "animais astuciosos", aproximada da proposta pragmatista, astúcia ligada ao poder inventivo, criativo e oferecendo alternativas práticas. Rorty afirma, que do ponto de vista utilitarista, "as crenças devem ser julgadas unicamente por sua utilidade em suprir as diversas necessidades desses animais (RORTY, 2009, p.58)". Com relação às aproximações entre James, Nietzsche e Mill, Rorty argumenta que, "Todos os três filósofos pensam que os termos 'verdadeiro' e 'justo' ganham seu significado do seu uso na avaliação do relativo sucesso dos esforços para se alcançar a felicidade (RORTY, 2009 p.58)". O pragmatismo traz a ideia de vantagem, de utilidade, e o perspectivismo de que podemos observar as questões/problemas de múltiplos modos. Enquanto que o utilitarismo prega a doutrina da busca pela felicidade humana.

Rorty aponta para o caráter imaginativo que repousa no romantismo, posto que este tenciona, "A substituição da religião pela poesia como fonte de ideias, um movimento que teve início com os românticos, parece-me ter sido proveitosamente descrita como um retorno ao politeísmo" (RORTY, 2009 p.59).

Rorty, no capítulo Pragmatismo e romantismo do livro Filosofia como política cultural, considera que, "No âmago do romantismo, encontra-se a tese da prioridade da imaginação sobre a razão - a afirmação de que a razão pode apenas seguir trilhas abertas pela imaginação.” (RORTY, 2009, p.179). A ideia monoteísta religiosa do Hebraísmo, que surge em oposição ao Helenismo, expressa por Arnold, dá lugar ao politeísmo romântico, mas que, contudo apresenta peculiaridades, posto que tais poetas apresentam diferentes aspectos da natureza humana ligados a "diferentes ideais". Sobre isso, Rorty nos informa que, "Um utilitarista romântico provavelmente abandonará a ideia de pessoas imortais diversificadas, tais como as divindades do Olimpo, mas conservará a ideia de que há formas de vida humana diversas, conflitantes, mas igualmente valiosas (RORTY, 2009, p.60)”. O politeísmo se apresenta como profusão de individualidades, como política democrática.

Ainda na referida obra, Rorty cita o texto de James intitulado As variedades da Experiência Religiosa, e em seguida comenta que “O uso livre que James faz do termo 'o divino’ o torna bastante equivalente a 'o ideal”' (RORTY, 2009 p.60). A questão religiosa apontada na perspectiva de James se assemelha, segundo Rorty, à proposta que Mill fez da política, ou seja, de que a finalidade ou "meta" é a diversidade de ideias. Sobre a relação do homem grego com o politeísmo ligado a ideia de pluralidade, Rorty citando Nietzsche, afirma que no período pré-socrático foi permitido “o luxo

\footnotetext{
${ }^{11}$ Asssim, como visto anteriormente, a ideia de contigencia se assenta na de alternativas outras, asssim como o perpectivismo se apoia na ideia de interpretações alternativas. É neste sentido que aproximamos os conceitos.
} 
da individualidade", e prossegue afirmando que, “[...] pela primeira vez foram honrados os direitos do indivíduos (RORTY, 2009 p.61)”. Passagem que remete ao projeto romântico em que o fazer estético se faz em conformidade com o político, onde é pela beleza que se chega à felicidade, à ideia de homem integral, que vive em harmonia com o todo e que se utiliza, sobretudo, da imaginação como ferramenta criativa.

Rorty acredita que, "somos politeístas se pensamos que não há um objeto de conhecimento real ou possível que nos permita medir e avaliar todas as necessidades humanas (RORTY, 2009 p.61)". Desse modo o autor apresenta um distanciamento que nos permite vislumbrar posturas ligadas a alternativas práticas. Assim podemos pensar em uma crítica antiteleológica que, por sua vez, nos conduziria à questões contingenciais. Rorty afirma que há no politeísmo um valor “coextensivo" entre este e o "Utilitarismo romântico (RORTY, 2009 p.62)", Sobretudo se ligado à ética proposta por Mill em Sobre a liberdade, tendo em vista que para este, a perfeição humana seria um assunto privado.

Seguindo esse fio politeísta, Rorty propõe que é esta privatização da perfeição que aproxima as perspectivas de James e Nietzsche assim como as de Mill e Arnold. Assinalando "que a poesia deveria assumir o papel que a religião tem desempenhado na formação das vidas humanas individuais (RORTY, 2009, p.62)". A figura do poeta romântico utilitarista é posta como a de um arauto que sinaliza tal potencial criativo e crítico, diferente do sacerdote monoteísta.

Rorty afirma, sobre a conduta politeísta e a postura nietzschiana, que:

Logo que alguém se torna politeísta, dará as costas não apenas aos sacerdotes, mas também aos substitutos de sacerdotes, como os físicos e os metafísicos - de quem quer que seja que se pretenda capaz de lhe dizer como as coisas realmente são, qualquer um que invoque a distinção entre o mundo verdadeiro e o mundo aparente que Nietzsche ridicularizou em O crepúsculo dos ídolos. (RORTY, 2009, p.62)

Parece haver, em certa medida, aproximações entre a crítica nietzschiana quanto à metafísica e a tradição filosófica, com o redescritivismo rortyano pela visão pragmatista e pela tentativa de oferecer outro projeto para a humanidade, distinto do modelo de representação que a filosofia secularizada oferecia. Como alvo temos a ideia de Realidade e de Verdade. Ambos conceitos basilares se pensamos na tradição filosófica desde Platão.

Rorty afirma ter demonstrado as similaridades e aproximações existentes entre os pensamentos de Nietzsche e Berthelot, e os pragmatistas norte-americanos, mas que gostaria doravante, de se voltar para as disparidades entre eles. Como mostra a seguinte passagem: 
Nietzsche achava que a democracia era um cristianismo para o povo - o cristianismo desprovido da nobreza de espírito de que o próprio Cristo, e talvez alguns poucos dos santos mais esforçados, foi capaz. Dewey achava que a democracia era um cristianismo purgado de seus elementos hieráticos, exclusionistas. Nietzsche achava que os que acreditavam em um Deus monoteísta tradicional eram fracos e tolos. Dewey os considerava como tão fascinados pela obra de um poeta que eram incapazes de apreciar as obras de outros poetas. Dewey achava que o tipo de ateísmo agressivo do qual Nietzsche se orgulhava era desnecessariamente intolerante. (RORTY, 2009, p.63)".

Rorty nos oferece elementos que demostrariam nítidas disparidades entre as duas vertentes mencionadas acima, colocando a visão nietzschiana como "extra incidental", exatamente pelo radicalismo e por seu caráter aparentemente intolerante. É enquanto a esse ponto que Rorty, em defesa de Dewey, diz ser esta sua "principal tarefa neste capítulo (p.63)", que seria "defender a tolerância de Dewey em relação à crença religiosa contra os que pensam que o pragmatismo e a religião não se misturam (RORTY, 2009, p.63)".

O utilitarismo nietzschiano apontado por Rorty diz respeito a uma dada maximização da felicidade, como dito anteriormente, é uma das características mais fundamentais do utilitarismo milleriano, mas que, contudo estaria restrito a um pequeno grupo, a seres humanos excepcionais, não a maioria, uma espécie de pensamento aristocrático, posto que "a democracia lhe parecia uma maneira de trivializar a existência humana (RORTY, 2009, p.64)", em contraste com a proposta fraterna universal oferecida por James e Dewey.

Nietzsche, segundo Rorty, parecia estar impressionado pelo que os valores cristãos, se comparados com os dos heróis homéricos pareciam "ridículos (RORTY, 2009, p. 65)". Rorty diz presumir que, seguindo a proposição nietzschiana "assim que a poesia tivesse substituído a religião como fonte de ideias, não haveria lugar nem para o cristianismo nem para a democracia (RORTY, 2009 p.65)". Rorty defende, tendo em vista essa passagem que para a perspectiva cristã não há nenhum judeu nem grego e a ideia de amor único não teria sido assimilada de forma acidental, de forma contingencial ao platonismo e segue afirmando que "esse ideal poderia ter se relacionado bem como o logocentrismo do Evangelho de João, ou sem a infeliz sugestão de Agostinho de que Platão havia prenunciado a verdade cristã (RORTY, 2009 p.65)". A ideia de Deus e de verdade eram consideradas unas na ótica cristã e quando se atacava uma delas, como fizeram os físicos como Newton, acabavam, por extensão, a atacar seus preceitos.

Como sabemos, o cristianismo é uma das principais matrizes interpretativas do modelo de pensamento ocidental. Daí a assertiva rortyana postular que "era natural, portanto, quando a ciência física começou a fazer progressos, que seus praticantes se apoderassem dessa retórica e, com isso, provocassem uma guerra entre a ciência e a teologia, entre a Verdade Científica e a Fé religiosa (RORTY, 2009 p.66)". 
No que poderíamos entender como um terceiro momento do texto O pragmatismo como um politeísmo romântico, o autor deixa de lado as desavenças entre Nietzsche e seus colegas norteamericanos a respeito do valor da democracia e nos comunica que se ocupará das diferenças entre Nietzsche, de um lado, e, James e Dewey de outro, acerca da crença religiosa. Com relação às disparidades entre estes pensadores, Rorty nos propõe que "Nietzsche pensa que a crença religiosa é intelectualmente descreditável; James e Dewey não concordam (RORTY, 2009, p.67)”. Desta forma, compreendemos que o pragmatismo é uma cooperação social ligada à intersubjetividade e destoa do autoconhecimento ou isolamento.

\section{3 - Considerações finais}

No presente estudo buscamos, através de argumentos, juntamente com nosso aporte teórico, apontar para as aproximaçãoes bem com os distanciamentos existentes entre a perspectiva nietzschiana e rortyana sobre o conceito de verdade. Para tanto dividimos este estudo em três tópicos com o intuito de pensar esse problema de forma suscinta, mas repeitando o rigor filosófico bem com o cuidado que se deve tomar quando tratamos de nomes tão importantes quanto ao fazer filosófico da contemporaneidade.

Os tópicos que compõe este artigo se dividiram em três partes. A primeira parte denominada "Nietzsche, verdade, conhecimento e crítica à modernidade", buscamos delinear de modo suscinto o percurso filosófico nietzschiano dando ênfase à sua critica quanto à ideia de verdade. Já no segundo tópico intitulado "Rorty, redescrição, verdade e neopragmatismo", semelhante ao trato dado às contribuições de Nietzsche, estudamos e apresentamos o expediente rortyano quanto à questão da verdade enlaçando nossa pesquisa com suas ideias. Enquanto que no terceiro e ultimo tópico, "Nietzsche como um pragmatista romântico", interpretamos a filosfia nietzschiana à luz do pragmatismo rortyano, dando ênfase para a discussão entre as aproximações e distanciamentos existentes entre a perspectiva apresentada pelos pragmatistas e a oferecida pela filosofia nietzschiana, ressaltando suas particularidades.

A ideia de verdade para o pragmatismo estaria ligada a um acordo intersubjetivo. Outra característica do pragmatismo é que este funciona como um dispositivo eficiente quanto uma dada ação, ou seja, só posso entender algo pela sua aplicabilidade prática. Só o signo verbal é um signo e apenas na interação intersubjetiva que tal ação prática se efetua. 


\section{4 - Bibliografia}

Nietzsche, Friedrich Wihelm, 1844-1900. Além do bem e do mal: prelúdio de uma filosofia do futuro. Friedrich; tradução de Mário Ferreira dos Santos. 4. ed.-Petrópolis, RJ: Vozes 2014. (coleção textos Filosóficos).

Genealogia da moral: uma polêmica. Friedrich Nietzsche; tradução, notas e posfácio Paulo César de Souza. - São Paulo: Companhia das Letras, 2009.

Verdade e mentira no sentido extramoral. In: Comum. Rio de Janeiro. Trad. Noéli Correia de Melo Sobrinho. v.6, n-17, p.05-23, 2001.

Rorty, Richard. A Filosofia e o espelho da natureza. Tradução Antônio Trânsito; revisão técnica César Ribeiro de Almeida. - Rio de Janeiro: Relume - Dumará, 1994.

. Contingência, ironia e solidariedade. Tradução de Vera Ribeiro. São Paulo: Martins, 2007.

Filosofia como política cultural. Tradução de João Carlos Pijnappel. - São Paulo: Martins Fontes, 2009. - (Coleção Dialética).

“Pragmatismo". in: Dicionário do pensamento contemporâneo. Direção de Manuel Maria Carrilho, Lisboa: D. Quixote, 1991. 